\title{
California Conservation Corps offers youth career development opportunities
}

Sally M. Stanley

Young people who leave high school without going on to college are a critical population to understand in terms of career development. This report highlights findings from a study of 166 youth who had recently joined the California Conservation Corps (CCC). Thirty percent of those surveyed had not completed high school. About one-fourth of the corps members had joined CCC with the hope of an eventual career with the Corps, and more than one-third were using $C C C$ to explore job and career opportunities.

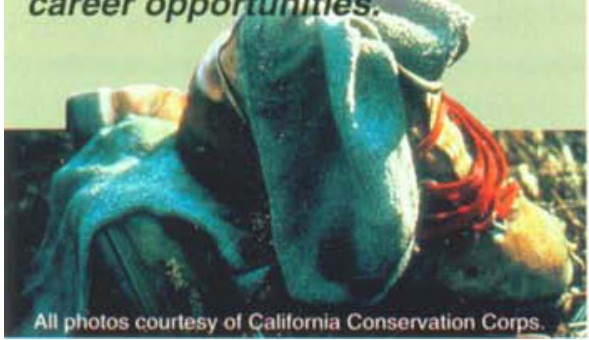

$\mathrm{F}^{\text {ntering the working world has }}$ Enever been an easy transition, but for young people today it involves many new challenges (see p. 48). Consequently, one would expect the first few years after high school to be a critical time in the lives of young people who do not go on to college. In today's labor market a college education is frequently required for work that can provide a decent income; as a rule, high school programs generally focus on preparing youth for college (Glover and Marshall 1993). However, in California, only $50.5 \%$ of students graduating from high school in 2000 entered a 4-year college program directly after high school, lower than the national average of $62.9 \%$ (Children Now 2001).

For some young people in California, the California Conservation Corps (CCC) presents an interesting alterna-

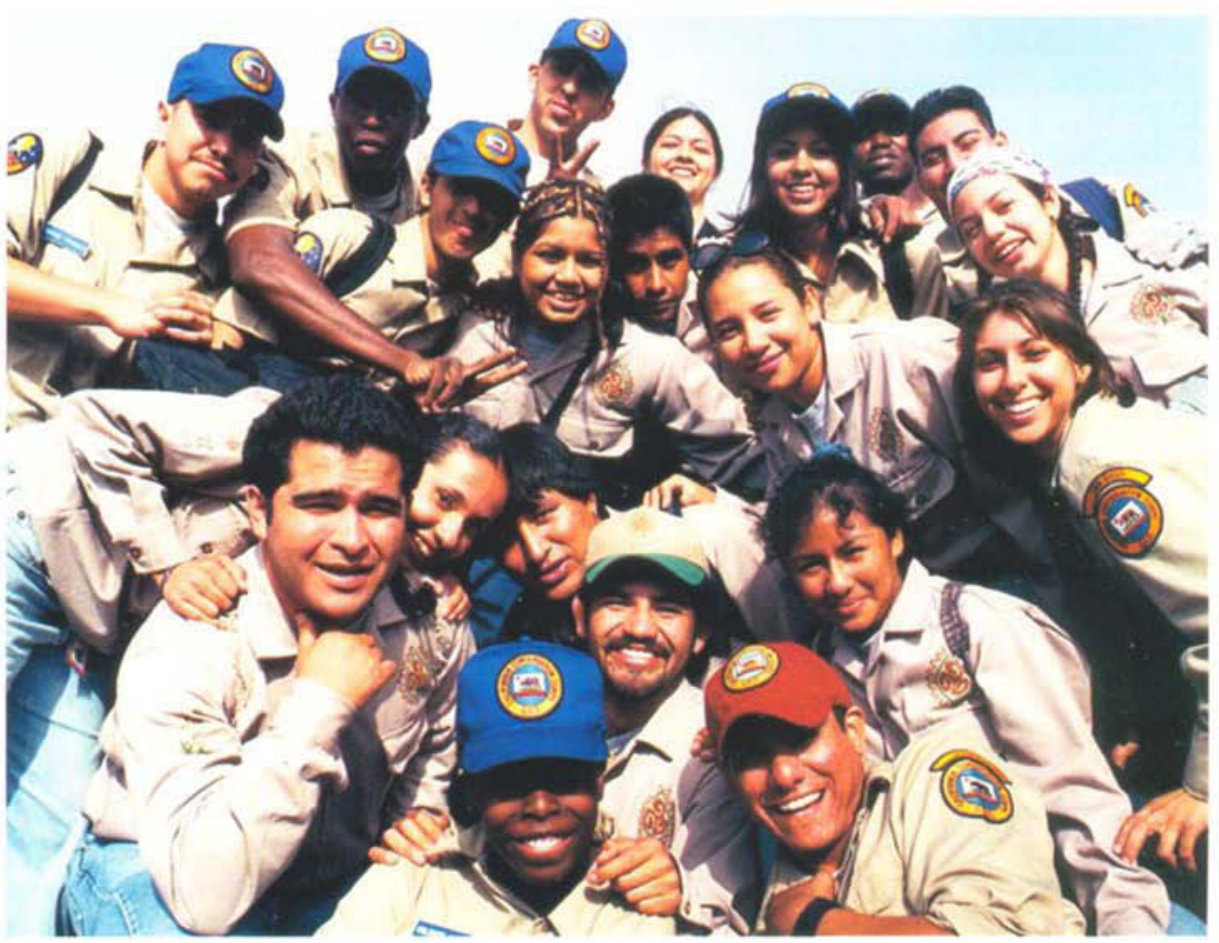

Since 1976, California Conservation Corps (CCC), a state agency, has provided employment for youth and labor for natural resource protection and enhancement. Today many young people also utilize the program for career development. Above, Corps members completed a project at the U.S.-Mexico border near San Diego.

tive to college. The program is considered one of the oldest and largest youth conservation corps programs in the United States today (Grossman and Tierney 1993), and currently operates as a service-learning program for exploring career options. Researchers at UC's 4-H Center for Youth Development (CYD) and their colleagues were interested in finding out if youth used the CCC program for career development. This study was conducted to investigate how reflective these young people were about their career choices and whether they were developing skills that would be helpful in the working world.

\section{Jobs for youth}

The California Legislature established the CCC in 1976 as an innovative state agency to focus on the employment and development of Cali- fornia youth, as well as the protection and enhancement of the state's natural resources. The CCC seeks to generate feelings of civic responsibility as well as provide labor needed for state projects. Along with its day-to-day conservation work and training, the CCC provides emergency assistance in floods, fires, oil spills or earthquakes.

The CCC offers an opportunity for California residents between the ages of 18 and 23 to participate in a worklearn program and to develop their career interests. Young persons applying to CCC must pass a physical exam, and they cannot be on probation or parole. Interested persons generally apply throughout the year at a CCC recruitment office. The number of youth allowed to participate varies by budget year. In 1997, the year the CYD study was conducted, the governor's office allotted 1,496 positions. How- 

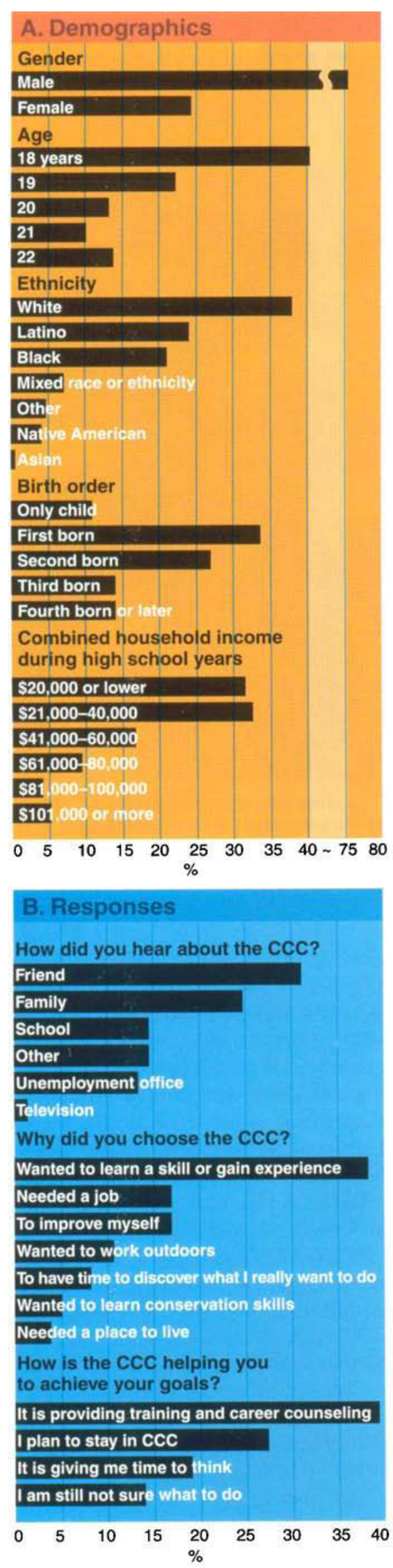

ever, 2,962 young people in California applied for the Corps that year. Generally, more applications are accepted than allotted because many of the applicants do not show up to their assigned district, and many leave after the program has started.

There are 11 geographical CCC districts throughout the state. Each district requests a specific number of recruits depending on the number of positions that need to be filled. Some districts are specialized for training in particular industries at specific times, as new needs develop. For example, when the survey was conducted the Auburn CCC district specialized in auto mechanics; Humboldt County had a salmon restoration program; and in San Luis Obispo County, youth were being trained in geographic information systems (GIS).

New recruits are allowed to look through a list of open positions at the various $\mathrm{CCC}$ sites and choose when and where to serve the Corps. Corps members are required to continue their educations by taking classes to earn a general equivalency diploma (GED) or enrolling at a community college. The CCC pays college tuition and costs associated with obtaining the GED.

Corps members can choose to live at home and report to work daily, or live in a dormitory in residential centers located at the CCC site. Corps members earn minimum wage for a typical 40-hour workweek, and can earn more for overtime. If they choose the residential option, a small amount (currently \$260) is deducted from their paychecks. If they live at home, they bring their own lunches; dormitory residents eat in dining halls and receive lunch. A typical workday begins at 8 a.m., and ends with evening

\section{Fig. 1. (A) Demographics of California} Conservation Corps (CCC) entrants participating in 1997 survey; and $(B)$ their responses to questions about the $C C C$ program. Percentages are based on total number of valid responses. Some respondents declined to answer some questions.

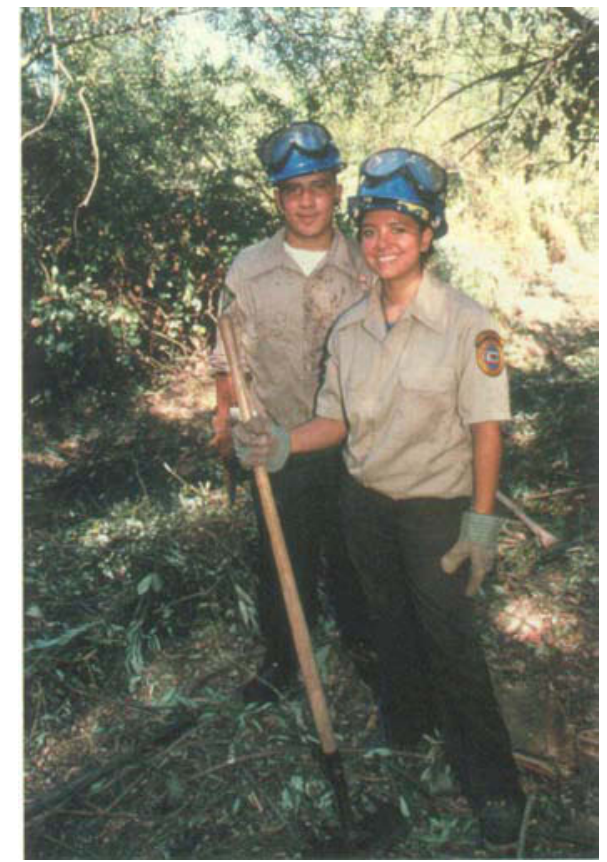

In 2002, about 2,000 CCC positions were allocated among 11 geographical regions. The majority of corps members are male and about $40 \%$ enter directly out of high school.

classes to continue their training. Corps members are on their own on the weekends, although the residential districts try to provide healthy activities.

Corps members are assigned to fill the current needs of the state. For example, they may do energy audits of government buildings, plant trees or clear brush or flood channels. They often work in state parks, and can be seen landscaping schools or maintaining medians on state highways. When there is a state emergency such as a flood or fire, crews from various districts are dispatched, and regular work stops until the emergency needs are met. Comments from alumni of the CCC program suggest that youth are quite proud of the contributions they make to the state during times of emergency.

All new and incoming corps members must attend Career Orientation Motivation and Education Training (COMET) classes that are designed to provide training in basic work ethics and information on career development. After completing 1 year in the program, corps members receive assis- 


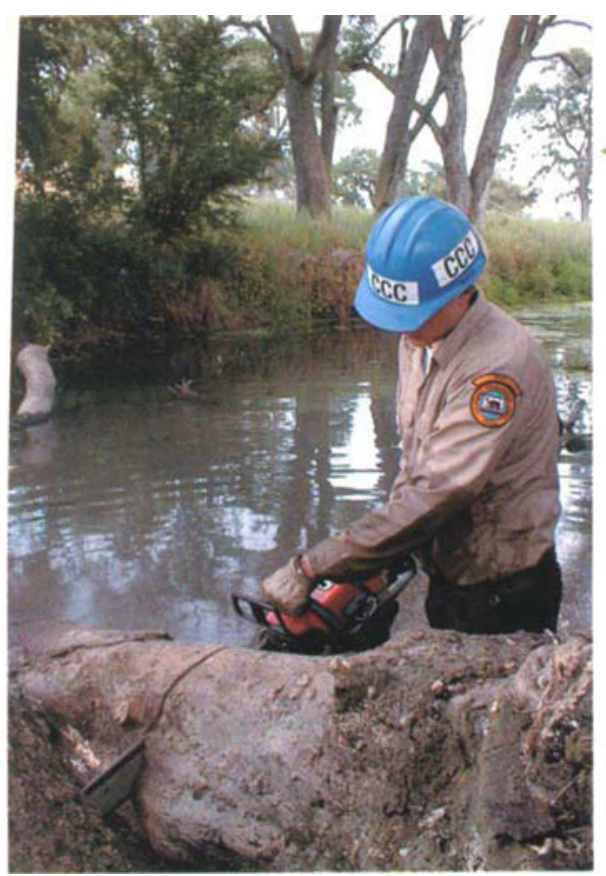

tance in locating employment, and a transition program guides them in tasks such as interviewing and resume writing. For example, CCC may help youth obtain entry-level positions with the Parks and Recreation Department. Some corps members (about 10\%) choose to pursue CCC as a career, for which they must pass a civil service exam.

Little research has been conducted on the CCC. However, in their 1993 evaluation Grossman and Tierney found that 58 to 63 months after participation in the program, CCC participants showed lower-paying jobs than youth in their comparison group. However, the authors acknowledged that their study design was flawed. Because CCC participants were more generally disadvantaged and more likely to have dropped out of high school, the study's findings were bi-
In a survey of 166 young people entering the corps, the CCC appeared to fulfill a career-counseling role for youths who did not take advantage of school-based services. A corps member works on a creek restoration project in the San Francisco Bay Area.

ased in favor of the comparison group. Grossman and Tierney therefore concluded that the comparison group only appeared to fare better than the CCC participants. Whereas Grossman and Tierney focused on financial outcomes for CCC participants, this study focuses on the use of the CCC program for career development.

\section{Career exploration at $\mathrm{CCC}$}

The 4-H CYD surveyed 166 incoming $\mathrm{CCC}$ recruits, in COMET classes in nine of the 11 state districts. All new recruits entering the program in June and July 1997 in each district participated. All corps members were allowed to take as long as needed to complete the 237-item, multiple-choice survey as well as several write-in questions. The survey requested information on demographics, family, school, reasons for selecting the Corps and future occupational goals. Corps members also took the Career Decision Profile (CDP) to measure career awareness (see p. 55)(Jones 1989). The term career awareness refers to reflective processes about future work life rather than decidedness. They also took a Career Key and a Task Specific Occupational Self-Efficacy Scale, which focus on personality variables; these have not yet been analyzed. A1though no formal interviews were

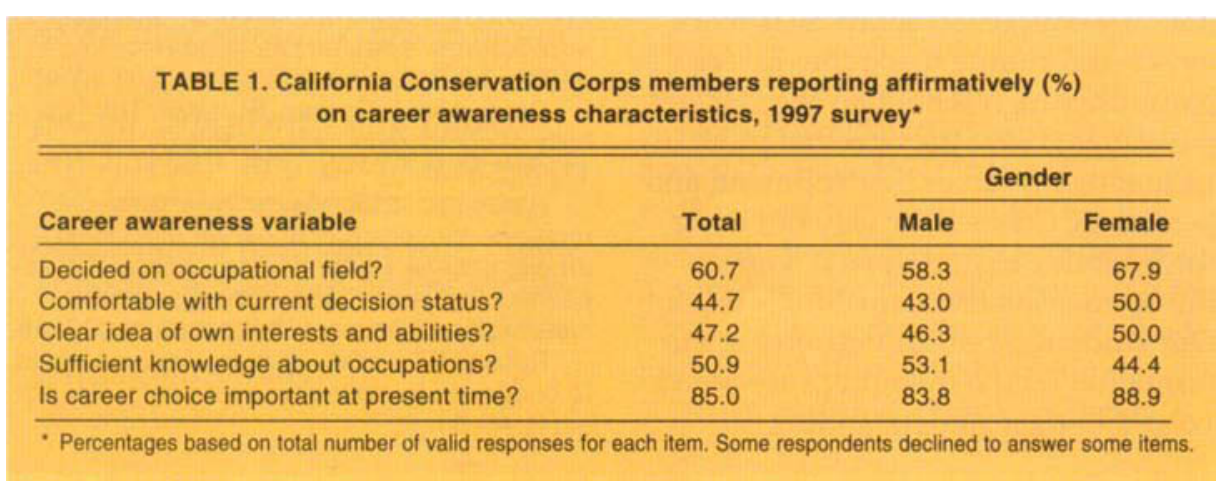

conducted, the researcher visited with youth and toured the sites.

Demographics. Although there was $100 \%$ participation at the sites surveyed, our sample includes only about $11.1 \%$ of the new CCC recruits for that calendar year. Most of the respondents were white, male and 18 or 19 years old (fig. 1A). Many corps members elected not to answer gender- or income-related questions. Almost half of those surveyed lived at the CCC site in a dormitory situation, while $27 \%$ lived at home with their parents. Although about one-fourth of the corps members hoped CCC would lead to a permanent career, most of the new recruits in our sample had joined to help develop their job skills and explore career opportunities (fig. 1B).

Career awareness. In general, $60.7 \%$ reported being decided on their career field. Of the total, only $44.7 \%$ were comfortable with their current decision status. Only $47.2 \%$ reported having a clear idea of their interests and abilities, and 50.9\% felt they had sufficient knowledge about occupations (table 1). However, $85 \%$ felt it was important to make a career choice at the present time. There were no significant differences noted between demographic characteristics and career awareness, though the older corps members were slightly less comfortable and more concerned about their lack of knowledge about careers.

Work histories. The research team was also interested in the previous work histories of the corps members. Work histories usually develop prior to the transition to adulthood (Entwisle et al. 2000). The majority of youth in the United States perform some type of paid work while in high school. Recent studies have shown that this does not affect academic performance unless youth work more than about 20 hours per week (see p. 55). Although $46 \%$ of the corps members surveyed said they had worked for pay while in high school, only $10.8 \%$ of this group said they worked in order to explore careers or gain work experience. Their attitude 
toward working was positive, but $48.6 \%$ of corps members who worked during high school said the main reason was to earn spending money. Saving for school (16.2\%), supplementing parents' income $(10.8 \%)$ and fun (13.5\%) were other reasons corps members listed. Corps members were divided into those who had worked during high school and those who had not, and into youth who were high or low on career decidedness. Of the youth who had worked, significantly more were in the highly decided group than in the low-decided group (chi-square, $P=0.051$ ).

Corps members. Sixty-eight percent of survey participants selfreported their high school grade point average (GPA) as 2.5 or less. Thirty percent $(30.2 \%)$ had not completed high school and were completing GEDs as part of the CCC program. When GPAs were divided into corps members who reported a $3.0 \mathrm{GPA}$ or higher versus those with 2.5 or lower, there was a significant relationship between dropping out of high school and having a lower GPA (chi-square, $P=0.000$ ).

There was also a relationship between GPA and reasons for joining the CCC. More youth with higher GPAs indicated they had joined CCC to learn a skill or gain experience, and youth with lower GPAs indicated they had joined CCC because they needed a job (chi-square, $P=0.024$ ). Of corps members who were continuing their education, only $15 \%$ thought they would obtain a college degree. Lack of finances and information were the two barriers youth felt most frequently prevented them from reaching their occupational goals.

Supportive influences. Corps members reported they had received the most support in career planning from their parents. Around 20\% stated they were unaware of any counseling programs offered in their high schools, and $24 \%$ said their high schools did not offer individual career counseling. A little over $18 \%$ said their high school did not offer classroom career counsel- ing, or any practical information. Almost $30 \%$ said that computerized career-counseling programs were not available. When programs were offered, $16 \%$ to $22 \%$ of corps members chose not to use them. Of corps members who did participate in high school counseling programs, only onefourth felt they were of any help. Of these, $33.2 \%$ said practical information — unrelated to careers, per se - - was most helpful, such as about financial aid or military services. Corps members who had completed high school were more likely to have used counseling services and know that they existed.

\section{The $\mathrm{CCC}$ alternative}

The CCC program provided us with some insight into the career exploration that continues after high school. Although dependent on the level of state government funding, the CCC offers an opportunity for many California young people to continue their career exploration while performing useful work for the state. The CCC also seemed to fill a career counseling role for youth who did not take advantage of counseling opportunities offered in their high schools.

Like Grossman and Tierney (1993), we found that most youth joining the CCC tended to be more economically and scholastically disadvantaged than most young people their age. However, our study did not focus on longterm outcomes but on the use of the program for career development. Although this study reports on only a small sample of participants in the CCC that year, it confirms that youth who do not continue on to college are not only concerned about their work lives but continue to explore career paths after high school. In the survey participants said they needed more information on career development, and joining CCC was their way of taking the initiative to understand some of the options available for future work. Our study did not provide enough information on the thought processes involved in their understanding of career development. Nor is it clear what type of information young people would find most useful.

California is faced with a projected increase of 5 million youth by 2025 (Russell 2000). These youth will need to find work. College is not the only alternative for gainful employment. There is also a definite need for qualified, skilled workers in occupations that do not require college, such as electricians, machinists and welders (Barrows 2000). What is needed now is a way to help fit the skills and interests of young workers with the needs of the workplace.

S.M. Stanley is Researcher, 4-H Center for Youth Development (CYD), Department of Human and Community Development, UC Davis. She would like to acknowledge Marc Braverman and the researchers at CYD and in the counties who participated on the research tearn as part of this project. She is also grateful to Robert Weisskirch, who collected data at two of the California Conservation Corps (CCC) sites, and Susanne Levitsky of CCC for helpful comments. This study was funded by the LC Division of Agriculture and Natural Resources and conducted in cooperation with the CCC.

\section{References}

Barrows M. 2000 Jan 17. Wrenching times for trade education. Sac Bee A1.

Children Now. 2001. California Report Card: Factors for School Success.

www.childrennow.org.

Entwisle DR, Alexander KL, Olson LS.

2000. Early work histories of urban youth. Am Sociol Rev 65(2):279-97.

Glover RW, Marshall R. 1993. Improving the school to work transition of American adolescents. Teachers College Rec 94(3):588-610.

Grossman J, Tierney JP. 1993. The fallibility of comparison groups. Evalua Rev 17(5):556-71

Jones LK. 1989. Measuring a threedimensional construct of career indecision among college students: A revision of the Vocational Decision Scale - The Career Decision Profile. J Counsel Psychol 36(4):477-86.

Russell ST. 2000. Third institution needed to bridge family-school gap for youth. Cal Ag 54(1):48-54. 